\title{
Therapeutic inertia in the management of hyperlipidaemia in type 2 diabetic patients: a cross-sectional study in the primary care setting
}

\author{
FY Man *, Catherine XR Chen, YY Lau, King Chan
}

\section{A B S T R A C T}

Objectives: To study the prevalence of therapeutic inertia in lipid management among type 2 diabetic patients in the primary care setting and to explore associated factors.

Methods: This was a cross-sectional study involving type 2 diabetic patients with suboptimal lipid control followed up in all general out-patient clinics of Kowloon Central Cluster in Hong Kong from 1 October 2011 to 30 September 2013. Main outcome measures included prevalence of therapeutic inertia in low-density lipoprotein management among type 2 diabetic patients and its association with patient and physician characteristics.

Results: Based on an agreed standard, lipid control was suboptimal in $49.1 \%(n=9647)$ of type 2 diabetic patients who attended for a regular annual check-up $(n=19662)$. Among the sampled 369 type 2 diabetic patients with suboptimal lipid control, therapeutic inertia was found to be present in 244 cases, with a prevalence rate of $66.1 \%$. When the attending doctors' profiles were compared, the mean duration of clinical practice was significantly longer in the therapeutic inertia group than the non-therapeutic inertia group.

This article was published on 17 Jun 2016 at www.hkmj.org. Doctors without prior training in family medicine were also found to have a higher rate of therapeutic inertia. Patients in the therapeutic inertia group had

longer disease duration, a higher co-morbidity rate of cardiovascular disease, and a closer-to-normal lowdensity lipoprotein level. Logistic regression analysis revealed that lack of family medicine training among doctors was positively associated with the presence of therapeutic inertia whereas patient's low-density lipoprotein level was inversely associated.

Conclusions: Therapeutic inertia was common in the lipid management of patients with type 2 diabetes in a primary care setting. Lack of family medicine training among doctors and patient's low-density lipoprotein level were associated with the presence of therapeutic inertia. Further study of the barriers and strategies to overcome therapeutic inertia is needed to improve patient outcome in this aspect of chronic disease management.
Hong Kong Med J 2016;22:356-64
DOI: $10.12809 / \mathrm{hkmj} 154667$
FY Man *, MB, BS, FHKCFP
CXR Chen, MRCP (UK), FHKAM (Family Medicine)
YY Lau, MB, BS, FHKAM (Family Medicine)
K Chan, FRACGP, FHKAM (Family Medicine)

Department of Family Medicine \& General Outpatient Clinic, Queen Elizabeth Hospital, Kowloon Central Cluster, Jordan, Hong Kong

* Corresponding author: mfy252@ha.org.hk

New knowledge added by this study

- Lipid control among patients with type 2 diabetes mellitus (T2DM) was far from satisfactory, with nearly half being suboptimally controlled.

- Therapeutic inertia (TI) is common in the lipid management of T2DM patients in the primary care setting with a prevalence rate of $66.1 \%$.

- Lack of family medicine training among doctors was positively associated with the presence of TI whereas patient's low-density lipoprotein level was inversely associated.

Implications for clinical practice or policy

- Comprehensive strategies should be devised to overcome TI so that long-term cardiovascular outcome of diabetic patients can be improved.

\section{Introduction}

Type 2 diabetes mellitus (T2DM) is one of the most common chronic conditions encountered in primary care, affecting up to $10 \%$ of the Hong Kong population. ${ }^{1}$ It is also a leading cause of morbidity and mortality due to diabetic complications. ${ }^{2}$ Optimal control of cardiovascular risk factors can decrease the risk of developing diabetes-related complications..$^{3-5}$
Hyperlipidaemia is one of the most important modifiable risk factors for cardiovascular disease (CVD) prevention. Studies have shown that optimal lipid control is associated with an improved cardiovascular outcome. ${ }^{6-9}$ Low-density lipoprotein (LDL) particles are considered more atherogenic than other cholesterol components and therefore stringent control of LDL is particularly important for the prevention of CVD in high-risk patients. ${ }^{10}$ 
Despite this evidence, lipid control among diabetic patients in the primary care setting, both locally and internationally, has been inadequate. ${ }^{11}$ The most recent study performed in Hong Kong found that $88.4 \%$ of diabetic patients had a suboptimal lipid level. ${ }^{12}$ Studies in Europe and the US found that the LDL control rate ranged from $30 \%$ to $55 \% .^{13-17}$ Similarly, a study of dyslipidaemia management in South Asia including China, South Korea, Malaysia, and Singapore revealed that only $48 \%$ of patients attained pre-defined low-density lipoprotein-cholesterol goals. ${ }^{18}$

Similar to other chronic conditions, the reasons for poor (lipid) control are multifactorial and may include patient, physician, and health care delivery factors. Among them, suboptimal medication augmentation has been identified as an important physician factor. This is known as therapeutic inertia (TI) and is said to exist whenever the health care provider does not initiate or intensify therapy appropriately when therapeutic goals are not reached: "recognition of the problem, but failure to act" ${ }^{19,20}$ Such TI has become increasingly acknowledged as a major impediment to CVD risk factor control. Studies have suggested that TI is related to the management of diabetes and hypertension (HT) and may contribute to up to $80 \%$ of heart attacks and strokes. ${ }^{21,22}$

The prevalence of TI in chronic disease management has not been explored in Hong Kong. In this study, we specifically looked at the prevalence of TI in hyperlipidaemia management among diabetic patients. Internal statistical data (internal data from Hospital Authority [HA] Head Office) revealed that lipid control has been relatively poor in this cluster when compared with blood pressure and glycaemic control. Our study aimed to explore the prevalence of TI in the management of hyperlipidaemia among T2DM patients and to explore the underlying factors. By overcoming the barriers to adequate and appropriate treatment, it was expected that the longterm cardiovascular outcome of T2DM patients could be improved.

\section{Methods}

\section{Subjects}

\section{Inclusion criteria}

In this cross-sectional study, all T2DM patients with International Classification of Primary Care code T90 (Non-insulin Dependent Diabetes Mellitus), who had been regularly followed up in all General Outpatient Clinics (GOPCs) of Kowloon Central Cluster (KCC) from 1 October 2011 to 30 September 2013, and had blood lipid levels checked at least once during this period were recruited. In our clinics, blood and urine check-ups are usually carried out in patients with T2DM every 12 to 18 months.

\section{探討二型糖尿病患者中高脂血症的臨床治療 慣性：來自基層醫療的橫斷面研究 文鳳兒、陳曉瑞、劉宇揚、陳景康}

目的：在基層醫療層面上探討二型糖尿病患者中高脂血症的臨床治療 慣性情況, 並找出相關因素。

方法：研究對象為2011年10月1日至2013年9月30日期間, 在九龍中 聯網普通科門診覆診而血脂水平末達標的二型糖尿病患者, 研究其血 脂控制的臨床治療慣性率以及與患者和醫生特性之間的關係。

結果：在19662例每年定期檢測的二型糖尿病患者中, 根據既定標 準，有49.1\%（9647例）的血脂控制不理想。在369個隨機抽樣病例 中, 244例 $(66.1 \%$ ) 出現臨床治療慣性。有臨床治療慣性的組別跟沒 有治療慣性的組別比較, 發現前者的主診醫生的平均臨床經驗較長, 沒有接受家庭醫學培訓的比率亦較高。出現臨床治療慣性的患者一般 病程較長, 有心血管疾病併發症的比率較高, 低密度脂蛋白水平近乎 接近正常。邏輯迴歸分析顯示沒有接受家庭醫學培訓與臨床治療慣性 呈正相關, 而患者的低密度脂蛋白水平則呈負相關。

結論：二型糖尿病患者高脂血症的臨床治療慣性在基層醫療很普遍。 醫生缺乏家庭醫學培訓以及患者的低密度脂蛋白水平與臨床治療慣性 相關。為改善慢性疾病的治療效果, 須進一步研究克服臨床治療慣性 的應對策略。

This 2-year retrieval period was therefore likely to cover all such patients regularly followed up in our cluster. The diagnosis of diabetes was based on the "Definition and description of diabetes mellitus" from American Diabetes Association (ADA) in $2013 .{ }^{23}$

\section{Exclusion criteria}

The following patients were excluded: patients who had been incorrectly diagnosed with diabetes, type 1 diabetic patients, diabetic patients who had no regular blood or urine check-up during the study period, diabetic patients followed up in a specialist clinic, and patients who died during the study period.

\section{Definition of treatment target and therapeutic inertia in lipid management among type 2 diabetic patients}

Various studies and guidelines have recommended targets in the treatment of hyperlipidaemia. In the HA of Hong Kong, National Cholesterol Education Program Adult Treatment Panel III Guidelines (NCEP ATP III) and ADA guidelines were used to set up the manual for the risk assessment and management programme. In this study, we used the same set of guidelines to define the level of lipid control in T2DM patients. We focused on the control of LDL as it is the most important risk factor of the lipid profile.

According to NCEP ATP III $2002^{24}$ and ADA 2013 Guidelines on Diabetes and Lipids, ${ }^{23}$ target LDL should be $<2.6 \mathrm{mmol} / \mathrm{L}$ in diabetic patients 
without overt CVD and $<1.8 \mathrm{mmol} / \mathrm{L}$ in diabetic patients with overt CVD. In this study, CVD is defined as established ischaemic heart disease (IHD), cerebrovascular accident (CVA), or peripheral vascular disease (PVD).

In this study, lipid control was defined as poor and escalation of treatment indicated if the last LDL level was $\geq 2.6 \mathrm{mmol} / \mathrm{L}$ in diabetic patients without CVD and $\geq 1.8 \mathrm{mmol} / \mathrm{L}$ in diabetic patients with established CVD. Consultation notes of the follow-up immediately after the last available lipid profile test were reviewed through the HA Clinical Management System (CMS). Therapeutic inertia was considered to be present when the attending doctor failed to initiate or intensify treatment if target LDL level was not achieved. If medical notes indicated a valid reason for non-escalation of treatment despite a clinical indication, it was not considered TI. Common justifications included:

(1) Diet and lifestyle modification advice was given to patients newly diagnosed with hyperlipidaemia.

(2) Statin was started following the previous visit and LDL level was improving.

(3) Patient was non-compliant with the existing statin regimen and advice on regular drug compliance was given.

(4) Patient refused to take a statin.

(5) Patient was unable to tolerate side-effects of statin.

(6) Statin was contra-indicated, eg in patients with deranged liver function.

\section{Calculation of sample size and random sampling}

According to the data drawn from Clinical Data Analysis and Reporting System of the HA, a total of 19662 T2DM patients were attending GOPCs of KCC for regular follow-up with checking of blood lipid profile during the study period. Based on the definitions mentioned above, 9647 of them had suboptimal or poor LDL control. Using the internet sample size calculator (Survey Software from Creative Research System, http://www. surveysystem.com), a sample size of 369 would provide $95 \%$ confidence level and 5\% margin of error. Thus, 400 patients were sampled to ensure adequate statistical power and allow room for case exclusion. A list of random numbers was then generated from the research randomiser (http://www.randomizer. org/form.htm), from which 400 patients were selected. Details of the visit with latest lipid profile result seen were recorded. Data were derived from the consultation notes in the CMS record of selected patients and recorded on a standard data collection form (Appendix). Data were collected by the principal investigator and counter-checked by another experienced doctor in the research team.

\section{Determination of variables}

Age and gender of all patients as well as smoking status, body mass index (BMI), latest blood pressure, haemoglobin A1c (HbA1c) level, serum creatinine level, lipid profile, and urine albumin-to-creatinine ratio were retrieved from the CMS. The most recent blood or urine test was used for analysis if more than one test had been performed during the study period. The BMI was calculated as body weight/ body height ${ }^{2}\left(\mathrm{~kg} / \mathrm{m}^{2}\right)$. The patient was considered a smoker if he/she currently smoked or had stopped in the last 6 months. ${ }^{25}$ The abbreviated Modification of Diet in Renal Disease formula was used to calculate the estimated glomerular filtration rate. ${ }^{26}$

The working profile of the attending doctors was retrieved from the Central Office of Department of Family Medicine (FM) and GOPC, KCC. Duration of clinical practice was calculated as the number of years from registration with the Medical Council of Hong Kong. The training status of FM of doctors was documented and categorised according to the following criteria:

- Group 1: Doctors who had never received any formal FM training.

- Group 2: Doctors who had completed basic vocational training from Hong Kong College of Family Physicians (HKCFP), or had studied the diploma of FM (DFM).

- Group 3: Doctors who were an intermediate fellow who had obtained fellowship in HKCFP.

- Group 4: Doctors were FM specialists who had obtained fellowship of the Hong Kong Academy of Medicine.

\section{Statistical analysis}

All data were entered and analysed using computer software (Windows version 21.0; SPSS Inc, Chicago [IL], US). Student's $t$ test and analysis of variance were used to analyse continuous variables and the Chi squared test for categorical data. Fisher's exact test was used if the sample size was less than five. Multivariate stepwise logistic regression was used to determine the association between TI and the significant different variables from patient characteristics and doctor characteristics. All statistical tests were two-sided, and a $\mathrm{P}$ value of $<0.05$ was considered statistically significant.

\section{Ethical considerations}

The study protocol was reviewed and approved by the Research Ethics Committee of HA (Kowloon Central/Kowloon East Cluster) [Reference number: KC/KE-13-0247/ER-1].

\section{Results}

A total of 21960 T2DM patients were identified from the KCC GOPC Diabetes Mellitus registry 
from 1 October 2011 to 30 September 2013. Among them, $19662(89.5 \%)$ patients had their lipid profile checked at least once during the study period; 9647 (49.1\%) cases had suboptimal lipid control based on the defined criteria above, including 1733 cases with co-existing CVD and 7914 cases without CVD.

Among 400 randomly sampled diabetic patients with suboptimal lipid control, 31 were excluded including 21 who were being followed up in other clinics for diabetic control, nine who died

TABLE I. Demographic characteristics of type 2 diabetic patients recruited into the study

\begin{tabular}{|c|c|}
\hline Characteristic & Data* $^{(n=369)}$ \\
\hline \multicolumn{2}{|l|}{ Gender } \\
\hline Male & $183(49.6 \%)$ \\
\hline Female & $186(50.4 \%)$ \\
\hline Age (years) & $65.5 \pm 11.9$ \\
\hline $\mathrm{BMI}\left(\mathrm{kg} / \mathrm{m}^{2}\right)$ & $25.5 \pm 4.0$ \\
\hline \multicolumn{2}{|l|}{ Smoking } \\
\hline Never & $263(71.3 \%)$ \\
\hline Smoker & 39 (10.6\%) \\
\hline Ex-smoker & $67(18.2 \%)$ \\
\hline Duration of DM (years) & $9.1 \pm 7.9$ \\
\hline Haemoglobin A1c (\%) & $7.0 \pm 1.2$ \\
\hline eGFR $\left(\mathrm{mL} / \mathrm{min} / 1.73 \mathrm{~m}^{2}\right)$ & $82.9 \pm 23.0$ \\
\hline \multicolumn{2}{|l|}{ Blood pressure } \\
\hline Systolic (mm Hg) & $131 \pm 16$ \\
\hline Diastolic (mm Hg) & $73 \pm 11$ \\
\hline Current use of statin & $101(27.4 \%)$ \\
\hline Simvastatin 5-10 mg daily & 75 \\
\hline Simvastatin $15-20$ mg daily & 23 \\
\hline Simvastatin $>20$ mg daily & 3 \\
\hline \multicolumn{2}{|l|}{ Co-morbidities } \\
\hline HT & 306 (82.9\%) \\
\hline CVD† & $62(16.8 \%)$ \\
\hline IHD & $24(6.5 \%)$ \\
\hline CVA & $40(10.8 \%)$ \\
\hline PVD & $2(0.5 \%)$ \\
\hline \multicolumn{2}{|l|}{ Lipid profile (mmol/L) } \\
\hline TG & $1.53 \pm 0.76$ \\
\hline $\mathrm{TC}$ & $5.12 \pm 0.74$ \\
\hline HDL & $1.36 \pm 0.57$ \\
\hline LDL & $3.12 \pm 0.61$ \\
\hline
\end{tabular}

Abbreviations: $\mathrm{BMI}=$ body mass index; CVA = cerebrovascular accident; CVD = cardiovascular disease; DM = diabetes mellitus; eGFR = estimated glomerular filtration rate; $\mathrm{HDL}=$ high-density lipoprotein; $\mathrm{HT}=$ hypertension $\mathrm{HD}=$ ischaemic heart disease; $\mathrm{LDL}=$ low-density lipoprotein; $\mathrm{PVD}=$ peripheral vascular disease; $\mathrm{TC}=$ total cholesterol; $\mathrm{TG}=$ triglyceride

* Data are shown as No. (\%) of cases or mean \pm standard deviation

† Some patients had more than one type of CVD

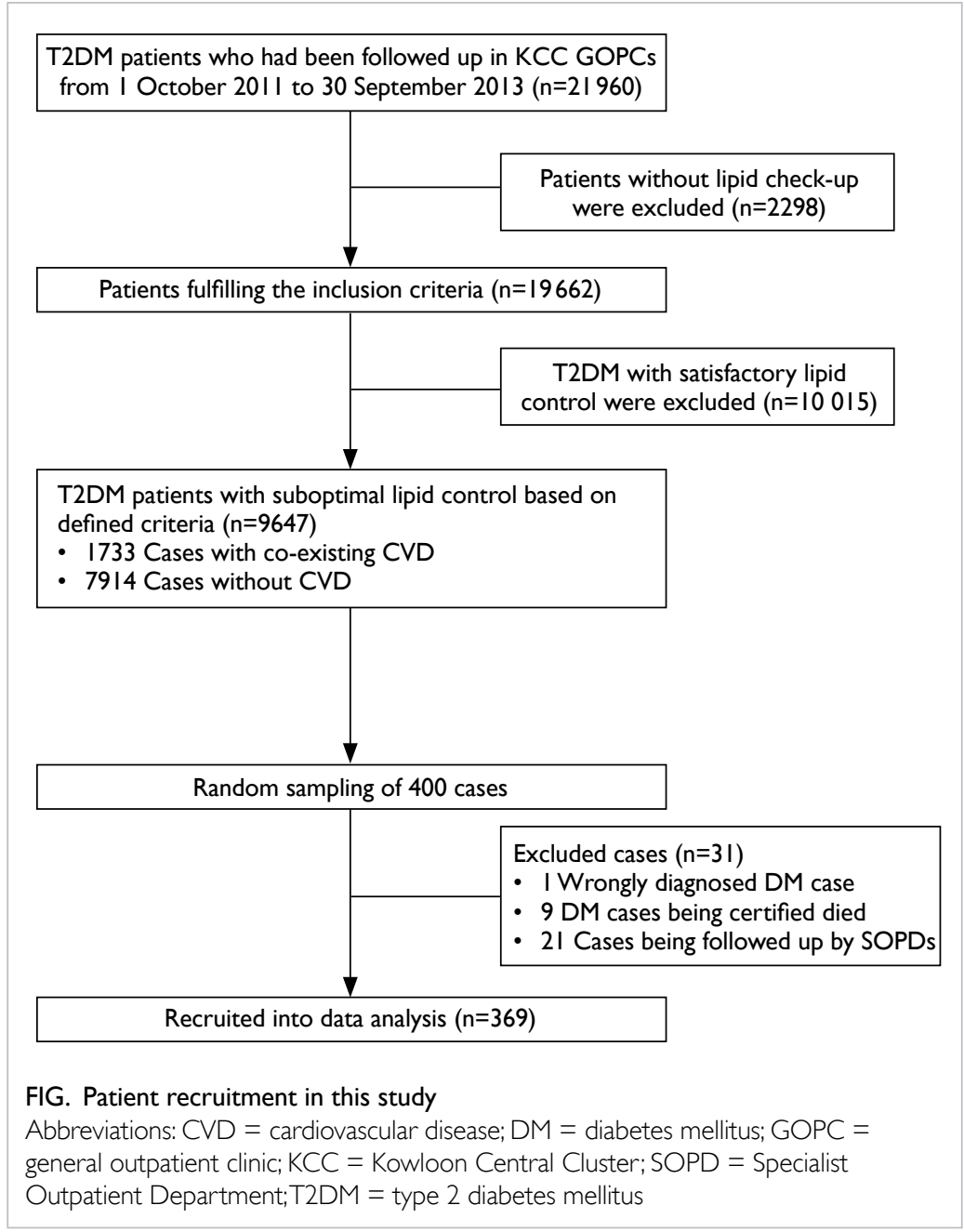

during the study period, and one who was wrongly diagnosed with diabetes. The remaining 369 cases were recruited for data analysis (Fig).

Table 1 summarises the demographic characteristics of the recruited patients. The mean $( \pm$ standard deviation) age of the study population was $65.5 \pm 11.9$ years and $186(50.4 \%)$ were female. The mean duration of diabetes was $9.1 \pm 7.9$ years. With regard to their co-morbidities, $306(82.9 \%)$ patients had concomitant HT, 24 (6.5\%) had IHD, 40 (10.8\%) had CVA, and two (0.5\%) had PVD. The mean LDL level was $3.12 \pm 0.61 \mathrm{mmol} / \mathrm{L}$ and only $101(27.4 \%)$ patients were prescribed a statin.

Table 2a summarises the demographic characteristics of the attending doctors. A total of 56 doctors, among whom 19 (33.9\%) were female, attended the 369 diabetic patients. The mean duration of clinical practice was $13.6 \pm 9.6$ years. With regard to FM training status, $13(23.2 \%)$ doctors had received no FM training, $18(32.1 \%)$ received basic training or studied DFM, $13(23.2 \%)$ were intermediate FM fellows, and 12 (21.4\%) were FM specialists.

Subanalysis of attending doctors' profile according to their duration of clinical practice and FM training status is shown in Table $2 \mathrm{~b}$. Training 
TABLE 2. (a) Demographic profile of physicians caring for the recruited patients with diabetes, and (b) subanalysis of attending doctors' profile according to duration of clinical practice and Family Medicine training status

(a)

\begin{tabular}{|lc|}
\hline Physician's characteristic & Data $^{*}(\mathbf{n}=\mathbf{5 6})$ \\
\hline Gender & \\
\hline Male & $37(66.1 \%)$ \\
\hline Female & $19(33.9 \%)$ \\
\hline Duration of clinical practice (years) & $13.6 \pm 9.6$ \\
\hline$\leq 5$ & $13(23.2 \%)$ \\
\hline $6-10$ & $12(21.4 \%)$ \\
\hline $11-20$ & $19(33.9 \%)$ \\
\hline$>20$ & $12(21.4 \%)$ \\
\hline FM training status & \\
\hline None & $13(23.2 \%)$ \\
\hline Basic FM training/DFM & $18(32.1 \%)$ \\
\hline Intermediate fellow & $13(23.2 \%)$ \\
\hline HKAM (FM) specialist & $12(21.4 \%)$ \\
\hline
\end{tabular}

(b)

\begin{tabular}{lcccccc}
\hline $\begin{array}{l}\text { Duration } \\
\text { of clinical } \\
\text { practice } \\
\text { (years) }\end{array}$ & None & $\begin{array}{c}\text { Basic FM } \\
\text { training/ } \\
\text { DFM }\end{array}$ & $\begin{array}{c}\text { Intermediate } \\
\text { fellow }\end{array}$ & $\begin{array}{c}\text { HKAM } \\
\text { (FM) } \\
\text { specialist }\end{array}$ & Total & P value \\
\hline 55 & 0 & 13 & 0 & 0 & 13 & $<0.001$ \\
$6-10$ & 0 & 0 & 9 & 3 & 12 & \\
$11-20$ & 4 & 5 & 3 & 7 & 19 & \\
$>20$ & 9 & 0 & 1 & 2 & 12 & \\
Total & $\mathbf{1 3}$ & $\mathbf{1 8}$ & $\mathbf{1 3}$ & $\mathbf{1 2}$ & $\mathbf{5 6}$ & \\
\hline
\end{tabular}

Abbreviations: DFM = Diploma of Family Medicine; FM = Family Medicine; HKAM =

Hong Kong Academy of Medicine

* Data are shown as No. (\%) of cases or mean \pm standard deviation status of FM varied significantly with duration of clinical practice $(\mathrm{P}<0.001)$. Among 13 doctors who had worked for $\leq 5$ years, all had been a basic FM trainee or had obtained a DFM. On the other hand, among 12 doctors who had worked for over 20 years, most $(n=9,75 \%)$ had not received any formal FM training.

Among the 369 recruited T2DM patients, treatment was escalated in 47 (12.7\%). Justification for not intensifying treatment was provided in 78 (21.1\%) cases. Justification was as follows: 19 patients were given dietary advice on lifestyle modifications as they were newly diagnosed with hyperlipidaemia; in 13 patients, a statin had been newly commenced at the previous visit and lipid level was lower compared with pretreatment; five patients were non-compliant with the existing treatment regimen and advice on compliance was given; 28 patients refused to start a statin despite medical advice; six patients had been unable to tolerate side-effects of statin. Statin therapy was contra-indicated in seven patients with impaired liver function. In the remaining 244 cases, TI was present with a prevalence rate of $66.1 \%$.

Table 3 shows the characteristics of physicians in TI-positive and TI-negative patients. The duration of clinical practice of attending doctors was significantly longer in the TI group compared with the non-TI group $(\mathrm{P}=0.001)$, with doctors working for over 20 years having a particularly higher rate of TI (82.4\%). Doctors without any FM training also had a higher rate of TI (77.7\%; P=0.006).

Table 4 summarises the characteristics of T2DM patients in TI-positive and TI-negative groups. Patients in the TI-positive group had a

TABLE 3. Comparison of the prevalence of $\mathrm{TI}$ according to profile of attending doctors

\begin{tabular}{|c|c|c|c|c|c|}
\hline Doctor's profile & $\begin{array}{c}\text { Total No. of } \\
\text { cases }(n=369)\end{array}$ & With TI (n=244) & $\begin{array}{l}\text { Without TI } \\
(n=125)\end{array}$ & $\begin{array}{c}\text { Prevalence of } \mathrm{TI} \\
(66.1 \%)\end{array}$ & $P$ value \\
\hline \multicolumn{6}{|l|}{ Gender } \\
\hline Male & 248 & 171 & 77 & $69.0 \%$ & 0.10 \\
\hline Female & 121 & 73 & 48 & $60.3 \%$ & \\
\hline \multicolumn{6}{|l|}{ Duration of clinical practice } \\
\hline Mean (years) & & $14.4 \pm 8.3$ & $11.7 \pm 7.0$ & & 0.001 \\
\hline$\leq 5$ & 56 & 35 & 21 & $62.5 \%$ & 0.007 \\
\hline $6-10$ & 108 & 63 & 45 & $58.3 \%$ & \\
\hline $11-20$ & 131 & 85 & 46 & $64.9 \%$ & \\
\hline$>20$ & 74 & 61 & 13 & $82.4 \%$ & \\
\hline \multicolumn{6}{|l|}{ Training status } \\
\hline Non-FM training & 94 & 73 & 21 & $77.7 \%$ & 0.006 \\
\hline FM training & 275 & 171 & 104 & $62.2 \%$ & \\
\hline Basic & 86 & 59 & 27 & $68.6 \%$ & \\
\hline Intermediate fellow & 106 & 59 & 47 & $55.7 \%$ & \\
\hline FM specialist & 83 & 53 & 30 & $63.9 \%$ & \\
\hline
\end{tabular}

Abbreviations: $\mathrm{FM}=$ Family Medicine; $\mathrm{TI}=$ therapeutic inertia 
longer duration of diabetes $(9.8 \pm 8.1$ years in TIpositive group vs $7.8 \pm 7.4$ years in TI-negative group; $\mathrm{P}=0.024$ ) and lower total cholesterol level and LDL level (both $\mathrm{P}<0.001$ ). The co-existence of CVD (IHD, CVA, PVD) was more common in the TI-positive group $(\mathrm{P}=0.003)$. Other characteristics including patient gender, age, BMI, smoking status, blood pressure, HbA1c level, and type and dose of current statin use were comparable for both groups (all $\mathrm{P}>0.05$ ).
Based on the results from Tables 3 and 4, multivariate stepwise logistic regression analysis was performed to identify any factors that contributed to TI (Table 5). Only variables that were significantly different in the univariate analysis were included in the regression model. As the FM training status varied significantly with the duration of clinical practice (Table $2 \mathrm{~b}, \mathrm{P}<0.001$ ) and these two factors were interrelated, only one of these two variables was included in the logistic regression analysis. As the P

TABLE 4. Patient profile in the presence or absence of TI*

\begin{tabular}{|c|c|c|c|}
\hline Patient characteristic & With TI (n=244) & Without TI $(n=125)$ & $P$ value \\
\hline \multicolumn{4}{|l|}{ Sex } \\
\hline Male & $120(49.2 \%)$ & $63(50.4 \%)$ & 0.824 \\
\hline Female & $124(50.8 \%)$ & $62(49.6 \%)$ & \\
\hline \multicolumn{4}{|l|}{ Age (years) } \\
\hline$<50$ & $18(7.4 \%)$ & $15(12.0 \%)$ & 0.246 \\
\hline $50-64$ & $90(36.9 \%)$ & $48(38.4 \%)$ & \\
\hline $65-74$ & $68(27.9 \%)$ & $37(29.6 \%)$ & \\
\hline$\geq 75$ & $68(27.9 \%)$ & $25(20.0 \%)$ & \\
\hline BMI $\left(\mathrm{kg} / \mathrm{m}^{2}\right)$ & $25.5 \pm 4.1$ & $25.6 \pm 3.9$ & 0.777 \\
\hline \multicolumn{4}{|l|}{ Smoking } \\
\hline Never & $172(70.5 \%)$ & $91(72.8 \%)$ & 0.512 \\
\hline Smoker & $24(9.8 \%)$ & $15(12.0 \%)$ & \\
\hline Ex-smoker & $48(19.7 \%)$ & $19(15.2 \%)$ & \\
\hline Duration of diabetes (years) & $9.8 \pm 8.1$ & $7.8 \pm 7.4$ & 0.024 \\
\hline Haemoglobin A1c (\%) & $7.0 \pm 1.2$ & $7.1 \pm 1.2$ & 0.339 \\
\hline eGFR $\left(\mathrm{mL} / \mathrm{min} / 1.73 \mathrm{~m}^{2}\right)$ & $82.4 \pm 23.6$ & $83.7 \pm 21.8$ & 0.613 \\
\hline $\mathrm{SBP}(\mathrm{mm} \mathrm{Hg})$ & $131 \pm 16$ & $129 \pm 15$ & 0.276 \\
\hline $\mathrm{DBP}(\mathrm{mmHg})$ & $73 \pm 11$ & $74 \pm 11$ & 0.268 \\
\hline Current use of statin & $60(24.6 \%)$ & $41(32.8 \%)$ & 0.094 \\
\hline Simvastatin 5-10 mg daily & $45(18.4 \%)$ & $30(24.0 \%)$ & 0.209 \\
\hline Simvastatin 15-20 mg daily & $13(5.3 \%)$ & $10(8.0 \%)$ & 0.315 \\
\hline Simvastatin >20 mg daily & $2(0.8 \%)$ & $1(0.8 \%)$ & 0.984 \\
\hline \multicolumn{4}{|l|}{ Co-morbidities } \\
\hline $\mathrm{HT}$ & $208(85.2 \%)$ & $98(78.4 \%)$ & 0.098 \\
\hline CVD† & $51(20.9 \%)$ & $11(8.8 \%)$ & 0.003 \\
\hline IHD & $21(8.6 \%)$ & $3(2.4 \%)$ & 0.022 \\
\hline CVA & 34 (13.9\%) & $6(4.8 \%)$ & 0.008 \\
\hline PVD & $2(0.8 \%)$ & 0 & 0.551 \\
\hline \multicolumn{4}{|l|}{ Lipid profile } \\
\hline $\mathrm{TG}(\mathrm{mmol} / \mathrm{L})$ & $1.48 \pm 0.67$ & $1.64 \pm 0.89$ & 0.059 \\
\hline $\mathrm{TC}(\mathrm{mmol} / \mathrm{L})$ & $5.00 \pm 0.63$ & $5.36 \pm 0.88$ & $<0.001$ \\
\hline HDL (mmol/L) & $1.38 \pm 0.67$ & $1.31 \pm 0.28$ & 0.224 \\
\hline LDL (mmol/L) & $2.99 \pm 0.49$ & $3.37 \pm 0.74$ & $<0.001$ \\
\hline
\end{tabular}

Abbreviations: $\mathrm{BMI}=$ body mass index; $\mathrm{CVA}=$ cerebrovascular accident; $\mathrm{CVD}=$ cardiovascular disease; $\mathrm{DBP}=$ diastolic blood pressure; $\mathrm{eGFR}=$ estimated glomerular filtration rate; $\mathrm{HDL}=$ high-density lipoprotein; $\mathrm{HT}$ = hypertension; $\mathrm{IHD}=$ ischaemic heart disease; $\mathrm{LDL}=$ low-density lipoprotein; $\mathrm{PVD}=$ peripheral vascular disease; $\mathrm{SBP}=$ systolic blood pressure; $\mathrm{TC}=$ total $\mathrm{cholesterol;TG}=$ triglyceride; $\mathrm{TI}=$ therapeutic inertia

* Data are shown as No. (\%) of cases or mean \pm standard deviation

$\dagger$ Some patients had more than one type of CVD 
TABLE 5. Logistic regression analysis of factors contributing to the presence of therapeutic inertia

\begin{tabular}{lcccc}
\hline Independent variable & Odds ratio & \multicolumn{2}{c}{ 95\% Cl for Exp(B) } & \multirow{2}{*}{ P value } \\
\cline { 3 - 4 } & & Lower & Upper & \\
\hline Lack of FM training & 2.170 & 1.230 & 3.829 & 0.008 \\
\hline Duration of diabetes (years) & 1.017 & 0.984 & 1.051 & 0.312 \\
Presence of CVD & 1.557 & 0.740 & 3.276 & 0.243 \\
Total cholesterol level & 1.035 & 0.619 & 1.733 & 0.895 \\
\hline LDL level & 0.320 & 0.159 & 0.643 & 0.001 \\
\hline
\end{tabular}

Abbreviations: $\mathrm{Cl}=$ confidence interval; $\mathrm{CVD}=$ cardiovascular disease; $\mathrm{FM}=$ Family Medicine; LDL = low-density lipoprotein

value of FM training status $(\mathrm{P}=0.006)$ was smaller than that for years of clinical practice $(\mathrm{P}=0.007)$ in the univariate analysis (Table 3 ), FM training status was entered into the logistic regression analysis. Lack of FM training was positively associated with TI (odds ratio $[\mathrm{OR}]=2.170 ; \mathrm{P}=0.008)$, whereas patient's $\mathrm{LDL}$ level was inversely associated $(\mathrm{OR}=0.320 ; \mathrm{P}=0.001)$.

\section{Discussion}

This was the first clinical analysis of TI in lipid management among T2DM patients managed locally in the primary care setting. It has provided important background information about the prevalence of TI in this group of patients. It also explored possible underlying factors from both the doctor's and patient's perspective.

Our study found that lipid control among T2DM patients was far from satisfactory, with $49.1 \%$ suboptimally controlled. This is consistent with reports that a high proportion of patients with hyperlipidaemia do not achieve their LDL goal. ${ }^{27,28}$ It is important to note that TI was present in $66.1 \%$ of these cases, meaning that in over $60 \%$ of diabetic patients with dyslipidaemia, appropriate management including dietary advice or drug treatment was not provided. This relatively high TI rate should alert primary care physicians to the importance of lipid control among T2DM patients as greater TI leads to poorer clinical outcomes. A similar study carried out by Whitford et $\mathrm{a}^{29}$ has shown that TI was present in $80 \%$ of consultations when lipid control was addressed among diabetic patients managed in the primary care setting in Middle East countries. This rate was much higher than the TI in blood pressure control (68\%) and glycaemic control (29\%). A similar study of lipid management in high-risk patients at a large academic primary care practice in the US has shown that statin dose was augmented at only $16 \%$ of over 2000 patient visits where the patient was suboptimally controlled. ${ }^{30}$ Among the sampled 369 poorly controlled T2DM patients in this study, only $27.4 \%(n=101)$ were treated with simvastatin, which is the only statin available in Hong Kong GOPCs.
In addition, most $(74.3 \%, 75 / 101)$ were treated with a lower dose (5-10 mg daily) that is considered inadequate according to ATP-IV guidelines in which a moderate dose of statin, such as simvastatin 20-40 mg daily, is recommended for T2DM patients in order to achieve target LDL level. ${ }^{31}$ Thus, the low statin prescription rate and the inadequate dose of statin may together contribute to the suboptimal lipid control among T2DM patients in primary care.

A possible explanation for the TI in dose augmentation of simvastatin is the potential drug-drug interaction with calcium channel blockers (CCB) such as amlodipine. ${ }^{32}$ The maximum recommended dose for simvastatin in conjunction with amlodipine use is $20 \mathrm{mg} /$ day. Since 306 (82.9\%) sampled diabetic patients were found to have concomitant HT and among them 122 (40\%) were prescribed amlodipine for blood pressure control, doctors might have hesitated to increase the dose of simvastatin. In our study, 10 diabetic patients in the TI-positive group were prescribed amlodipine and simvastatin $20 \mathrm{mg}$ daily. In this scenario, either changing simvastatin to an alternative statin such as atorvastatin or changing amlodipine to an alternative CCB such as nifedipine is recommended if lipid control remains suboptimal. Failing to switch to another statin or CCB when clinically indicated is also considered to be TI. A more proactive approach to prescribing different drug combinations is required in order to achieve the target LDL in a timely manner.

Further studies of the physician profile relative to the presence of TI have revealed that doctors with longer duration of clinical practice have a higher rate of TI that is even more prominent in those with over 20 years' clinical practice. These findings are contrary to an overseas study where more experienced doctors had a lower rate of $\mathrm{TI}^{33}$; nonetheless, this study was performed in a secondary care setting and involved cardiologists who managed hyperlipidaemia in patients with IHD. In our study, most doctors who had worked for over 20 years had no formal FM training (9 [75\%] of 12 doctors; Table $2 b)$. In addition, when training status was compared, doctors with no FM training had a higher rate of TI than those who had completed FM training $(77.7 \%$ vs $60.0 \%$; $\mathrm{P}=0.006)$. We postulate that doctors who have worked for over 20 years may be less familiar with the latest guidelines on lipid management, possibly due to a lack of FM or related training. If physicians lack appropriate training, there will be gaps in their knowledge of latest clinical management guidelines. This has been confirmed by review articles which showed that TI could be attributed to insufficient knowledge of guidelines. ${ }^{34}$

When patient's profile was compared, surprisingly, TI was present in 51 of 62 diabetic patients with overt CVD, and only 11 cases were properly managed (Table 4 ). This is a considerable concern since lipid control is particularly important 
and as a secondary prevention strategy in this group of patients. The target for LDL control is much more stringent at $<1.8 \mathrm{mmol} / \mathrm{L}$ in this group of patients, and more difficult to achieve clinically. Some doctors may not have been aware of this stricter/lower LDL target and have been satisfied with LDL level of 1.8 to $2.6 \mathrm{mmol} / \mathrm{L}$. This is supported by our finding that among diabetic patients with overt CVD whose lipid profile was inadequately controlled $(n=62)$, more than half $(n=33,53.2 \%)$ had LDL controlled at 1.8 to $2.6 \mathrm{mmol} / \mathrm{L}$. Physicians should take a more proactive approach particularly in this high-risk group of patients and adhere closely to the prevailing management guidelines in CVD risk factor control.

Multiple variable logistic regression analysis revealed that patients with lower LDL or LDL level closer to normal was associated with TI (Table 5). This could be explained by the threshold effect, that is, the closer the LDL level is to target level, the less likely is the doctor to intensify treatment. This threshold effect has been commonly observed in other similar studies. ${ }^{30,35}$ Other factors that contribute to the threshold effect could be 'overestimation of current care' or 'complacency with borderline values', leading to the physician's subjective misperception that the care provided is sufficient. ${ }^{34}$

\section{Implications for primary care}

Our study found that TI was common in lipid management among diabetic patients managed in the GOPCs of KCC, with a prevalence of $66.1 \%$. Doctors with a longer duration of clinical practice and who had not received formal FM training had a higher rate of TI. Patients with a closer-to-target LDL were more common in the TI group. Considering that a large volume of diabetic patients are managed in the primary care setting, comprehensive strategies with a more proactive approach should be devised to combat TI so that the cardiovascular outcome of diabetic patients can be improved.

\section{Strengths and limitations of the study}

This is the first clinical analysis of TI in lipid management among diabetic patients managed locally in the primary care setting. It has provided important background information about the prevalence of TI in lipid management among diabetic patients and explored the possible underlying factors from both the doctor's and patient's perspective. These findings will help improve strategies to overcome TI in lipid control for these patients.

There are some limitations in this study. First, the study was carried out in one single cluster of HA and therefore selection bias might exist. These results from the public primary health care sector might not be applicable to the private sector or secondary care. In addition, the number of doctors with or without FM training was quite discrepant in this study (43 vs 13) and may affect the generalisation of findings. Nevertheless, the present results may lay the groundwork for similar studies in the future, both locally and internationally. Second, patients with diabetes who had not had any blood testing performed during the study period were excluded $(\mathrm{n}=2298$, $10.5 \%$ of all diabetic cases). The lipid control status of this group of diabetic patients remained unknown. This might bias the accurate measurement of TI among our target population. Third, only TI in LDL management was explored in this study. Management of hypertriglyceridaemia was not addressed in view of its less-important role as a risk factor for CVD. Future studies exploring the TI in hypertriglyceridaemia management are needed to comprehensively assess lipid control among diabetic patients. Lastly, this study relied heavily on review of consultation notes to identify justification for submaximal therapy and determine presence of TI. Insufficient justification for a certain treatment may have resulted in an overestimation of the prevalence of TI.

\section{Conclusions}

This study found that TI was common in the lipid management of diabetic patients managed in GOPCs of KCC, with a prevalence rate of $66.1 \%$. Doctors without FM training and a closer-to-target LDL level among T2DM patients were associated with the presence of TI. Comprehensive strategies should be devised to overcome TI so that the cardiovascular outcome of diabetic patients can be improved.

\section{Acknowledgements}

We are indebted to Ms Katherine Chan, statistical officer of Queen Elizabeth Hospital, for her expert statistical support in the data analysis.

\section{Appendix}

Additional material related to this article can be found on the HKMJ website. Please go to <http:// www.hkmj.org $>$, and search for the article.

\section{Declaration}

All authors have disclosed no conflicts of interest.

\section{References}

1. Chan JC, Malik V, Jia W, et al. Diabetes in Asia: epidemiology, risk factors, and pathophysiology. JAMA 2009;301:2129-40.

2. Leung GM, Lam KS. Diabetic complications and their implications on health care in Asia. Hong Kong Med J 2000;6:61-8.

3. Colhoun HM, Betteridge DJ, Durrington PN, et al. Primary prevention of cardiovascular disease with atorvastatin in type 2 diabetes in the Collaborative Atorvastatin Diabetes Study (CARDS): multicentre randomised placebocontrolled trial. Lancet 2004;364:685-96.

4. Collins R, Armitage J, Parish S, Sleigh P, Peto R; Heart 
Protection Study Collaborative Group. MRC/BHF Heart Protection Study of cholesterol-lowering with simvastatin in 5963 people with diabetes: a randomised placebocontrolled trial. Lancet 2003;361:2005-16.

5. Gaede P, Vedel P, Larsen N, Jensen GV, Parving HH, Pedersen O. Multifactorial intervention and cardiovascular disease in patients with type 2 diabetes. $\mathrm{N}$ Engl J Med 2003;348:383-93.

6. Waters DD, Ku I. Early statin therapy in acute coronary syndromes: the successful cycle of evidence, guidelines, and implementation. J Am Coll Cardiol 2009;54:1434-7.

7. Ward S, Lloyd Jones M, Pandor A, et al. A systematic review and economic evaluation of statins for the prevention of coronary events. Health Technol Assess 2007;11:1-160,iii-iv.

8. O’Regan C, Wu P, Arora P, Perri D, Mills EJ. Statin therapy in stroke prevention: a meta-analysis involving 121,000 patients. Am J Med 2008;121:24-33.

9. Vrecer M, Turk S, Drinovec J, Mrhar A. Use of statins in primary and secondary prevention of coronary heart disease and ischemic stroke. Meta-analysis of randomized trials. Int J Clin Pharmacol Ther 2003;41:567-77.

10. Law MR, Wald NJ, Rudnicka AR. Quantifying effect of statins on low density lipoprotein cholesterol, ischaemic heart disease, and stroke: systematic review and metaanalysis. BMJ 2003;326:1423.

11. Fung CS, Chin WY, Dai DS, et al. Evaluation of the quality of care of a multi-disciplinary risk factor assessment and management programme (RAMP) for diabetic patients. BMC Fam Pract 2012;13:116.

12. Kung K, Chow KM, Hui EM, et al. Prevalence of complications among Chinese diabetic patients in urban primary care clinics: a cross-sectional study. BMC Fam Pract 2014;15:8.

13. Kotseva K, Wood D, De Backer G, De Bacquer D, Pyörälä K, Keil U; EUROASPIRE Study Group. Cardiovascular prevention guidelines in daily practice: a comparison of EUROASPIRE I, II, and III surveys in eight European countries. Lancet 2009;373:929-40.

14. Toth PP, Zarotsky V, Sullivan JM, Laitinen D. Dyslipidemia treatment of patients with diabetes mellitus in a US managed care plan: a retrospective database analysis. Cardiovasc Diabetol 2009;8:26.

15. Ferrières J, Gousse ET, Fabry C, Hermans MP; French CEPHEUS Investigators. Assessment of lipid-lowering treatment in France-the CEPHEUS study. Arch Cardiovasc Dis 2008;101:557-63.

16. Kotseva K, Stagmo M, De Bacquer D, De Backer G, Wood D; EUROASPIRE II Study Group. Treatment potential for cholesterol management in patients with coronary heart disease in 15 European countries: findings from the EUROASPIRE II survey. Atherosclerosis 2008;197:710-7.

17. Santos RD, Waters DD, Tarasenko L, et al. Low- and high-density lipoprotein cholesterol goal attainment in dyslipidemic women: The Lipid Treatment Assessment Project (L-TAP) 2. Am Heart J 2009;158:860-6.

18. Kim HS, Wu Y, Lin SJ, et al. Current status of cholesterol goal attainment after statin therapy among patients with hypercholesterolemia in Asian countries and region: the Return on Expenditure Achieved for Lipid Therapy in Asia (REALITY-Asia) study. Curr Med Res Opin 2008;24:1951-63.

19. Phillips LS, Branch WT, Cook CB, et al. Clinical inertia. Ann Intern Med 2001;135:825-34.

20. Okonofua EC, Simpson KN, Jesri A, Rehman SU, Durkalski
VL, Egan BM. Therapeutic inertia is an impediment to achieving the Healthy People 2010 blood pressure control goals. Hypertension 2006;47:345-51.

21. Andrade SE, Gurwitz JH, Field TS, et al. Hypertension management: the care gap between clinical guidelines and clinical practice. Am J Manag Care 2004;10:481-6.

22. O'Connor PJ, Sperl-Hillen JM, Johnson PE, Rush WA, Biltz G. Clinical inertia and outpatient medical errors. In: Henriksen K, Battles JB, Marks ES, Lewin DI, editors. Advances in patient safety: from research to implementation. Vol 2: Concepts and methodology. Rockville (MD): Agency for Healthcare Research and Quality (US); 2005.

23. American Diabetes Association. Standards of medical care in diabetes-2013. Diabetes Care 2013;36 Suppl 1:S11-66.

24. National Cholesterol Education Program (NCEP) Expert Panel on Detection, Evaluation, and Treatment of High Blood Cholesterol in Adults (Adult Treatment Panel III). Third Report of the National Cholesterol Education Program (NCEP) Expert Panel on Detection, Evaluation, and Treatment of High Blood Cholesterol in Adults (Adult Treatment Panel III) final report. Circulation 2002;106:3143-421.

25. Centers for Disease Control and Prevention (CDC). Smoking-attributable mortality, years of potential life lost, and productivity losses-United States, 2000-2004. MMWR Morb Mortal Wkly Rep 2008;57:1226-8.

26. Levey AS, Bosch JP, Lewis JB, Greene T, Rogers N, Roth D. A more accurate method to estimate glomerular filtration rate from serum creatinine: a new prediction equation. Modification of Diet in Renal Disease Study Group. Ann Intern Med 1999;130:461-70.

27. Park JE, Chiang CE, Munawar M, et al. Lipid-lowering treatment in hypercholesterolaemic patients: the CEPHEUS Pan-Asian survey. Eur J Prev Cardiol 2012;19:781-94.

28. Khoo CM, Tan ML, Wu Y, et al. Prevalence and control of hypercholesterolaemia as defined by NCEP-ATPIII guidelines and predictors of LDL-C goal attainment in a multi-ethnic Asian population. Ann Acad Med Singapore 2013;42:379-87.

29. Whitford DL, Al-Anjawi HA, Al-Baharna MM. Impact of clinical inertia on cardiovascular risk factors in patients with diabetes. Prim Care Diabetes 2014;8:133-8.

30. Goldberg KC, Melnyk SD, Simel DL. Overcoming inertia: improvement in achieving target low-density lipoprotein cholesterol. Am J Manag Care 2007;13:530-4.

31. Stone NJ, Robinson J, Lichtenstein AH, et al. 2013 ACC/ AHA Guideline on the Treatment of Blood Cholesterol to Reduce Atherosclerotic Cardiovascular Risk in Adults, Journal of the American College of Cardiology 2013. Available from: https://www.joslin.org/docs/2013-ACCAHA-Guideline-Treatment-of-Blood-Cholestero-_toReduce-Atherosclerotic-Cardiovascular-Risk-in-Adults. pdf. Accessed Mar 2016.

32. Simvastatin summary of product characteristics. Available from: http://www.medicines.org.uk/emc/medicine/1201/ SPC. Accessed Mar 2016.

33. Aujoulat I, Jacquemin P, Rietzschel E, et al. Factors associated with clinical inertia: an integrative review. Adv Med Educ Pract 2014;5:141-7.

34. Byrnes PD. Why haven't I changed that? Therapeutic inertia in general practice. Aust Fam Physician 2011;40:24-8.

35. Berlowitz DR, Ash AS, Glickman M, et al. Developing a quality measure for clinical inertia in diabetes care. Health Serv Res 2005;40:1836-53. 